\title{
Figural aftereffect potency: A function of sex or field-dependence? ${ }^{1}$
}

\author{
LUDWIG IMMERGLUCK, San Francisco \\ State College, San Francisco, Calif. 94132
}

In a series of previous investigations, a relationship between figural aftereffect potency and measures of field dependence was uncovered. More specifically, field-independent Ss exhibited more potent aftereffects than did field-dependent $S$ s. In order to rule out the possibility that a $S$ 's sex rather than field-dependence attribute determines aftereffect magnitude, the present investigation controlled both sex and field-dependence parameters. The results show that field-dependence measures rather than sex relate to aftereffect potency.

A series of recent investigations (Immergluck, 1966a, b, 1968) related individual differences in visual figural aftereffect potency to measures of field-dependence. More specifically, these experimental investigations showed that field-independent Ss, as assessed by the Rod and Frame Test, exhibited more potent aftereffects than did field-dependent Ss. It was reasoned that field-dipendent Ss, who are presumably more directly and concretely bound to whatever stimulus field confronts them at the moment, are in an aftereffect sequence more forcefully influenced by the $\mathrm{T}$-figure characteristics and respond accordingly. In other words, whatever trace residue might be left, following perceptual fixation of the I figure, it is readily obliterated by the impact of the subsequently exposed $T$ figure. Field-independent $S$, on the other hand, being less swayed perceptually by immediately present stimulus patterns, maintain I-figure trace residues, even while inspecting the now-present $T$ figure, which interact with the new stimulus configuration-yielding an aftereffect.

Repeated studies, including the employment of different aftereffect stimulus patterns (Immergluck, 1968) have corroborated the relationship between the magnitude of an aftereffect and measures of field dependence. Recently, however, it was suggested (Pressey \& Koffman, 1968) that this found relationship may be due to an experimental artifact in which underlying sex differences, that may possibly account for the obtained differences in aftereffect magnitude, might have been masked by the experimental design employed. More specifically, it was conjectured that since the pertinent literature shows a greater abundance of field-independent Ss among unselected male groups as compared to females who typically yield a higher percentage of field-dependent measures, the experimental groups employed by Immergluck might have contained greater densities of male and female Ss, respectively, for the field-independent and field-dependent groups. Actually, care was taken in those investigations to avoid an overloading of male or female Ss for each of the experimental groups, although no separate analyses were made for the male and fermale Ss.

The present investigation aims to clarify this issue by exploring specifically the potential effects of sex vs field-dependence in relationship to aftereffect potency. Both sex and field-dependence measures, then, have been controlled in the research design, thus permitting direct comparison of these two $S$ attributes as they affect perceptual aftereffect performance. Furthermore, in order to make the presently obtained data more directly relevant to the previously cited investigations, the identical aftereffect figures and the same experimental conditions were employed in the present study.

\section{METHOD}

The $S$ groups, college students ranging in age from 19 to 22 years, were selected, as in the previous investigations, on the basis of their performance on the Rod and Frame Test (op. cit.). Those Ss who were able to place the rod consistently during 10 trials within $3 \mathrm{deg}$ of the true vertical position (disregarding the tilt of the frame) were placed in the field-independent group, while those who made errors of $10 \mathrm{deg}$ or more were assigned to the field-dependent group. All Ss were selected from larger $S$ pools until the final $S$ groups of 40 field-independent Ss-comprised of 20 males and 20 females-and 40 field-dependent Ss, also comprised of 20 male and 20 female $\mathrm{Ss}$, were established.

All Ss were then exposed to the identical figural aftereffect test: the I figure, consisting of two different sized squares, one measuring $1 \mathrm{in}$., the other $1.5 \mathrm{in}$., separated equally by $2 \mathrm{in}$. from their respective centers to the central fixation point. Following a fixation time of $30 \mathrm{sec}$, the $\mathrm{T}$ figure, consisting of two identical 1.5-in. squares, was immediately presented to $S$ who was required to identify the test squares as "equal" or "unequal." Presence of the aftereffect is demosntrated by a S's perception of the objectively identical test squares as "unequal."

The assessment of field dependence (i.e., administration of the Rod and Frame Test) and the administration of the aftereffect task was carried out by two separate Es, so that during the course of the study neither $S$ nor $E$ who administered the aftereffect task had information regarding the S's field-dependence score.

\section{RESULTS AND DISCUSSION}

Table 1 demonstrates clearly the relationship between measures of field-dependence and aftereffect potency. As can be seen, no matter what the sex of the $S$ is, field-independent males and field-independent females exhibited significantly more aftereffect responses than did field-dependent males or field-dependent females $(p<0.01)$.

Since the pertinent research literature has by now amply demonstrated that a greater number of field-independent Ss can be obtained from randomly selected male groups as compared to female $S$ groups, it should certainly also be expected that male Ss, as a group, should yield more potent aftereffect responses than female Ss. However, as the present investigation shows, once control for sex has been instituted, the significant variable that relates to aftereffect potency is a S's measure of field dependence.

Finally, attention is drawn to a methodological issue. Dodwell (1969) has recently suggested the possibility that both field dependence and aftereffect performance may be the resultants of inadvertent set-induced influences on the part of the $E$. This entire issue demands more discussion than can be given here, but since great care was taken to employ separate Es for the assessment of these two perceptual variables in the present investigation, such potential E-induced sets can be ruled out.

Table 1

A Sex and Field Dependence Comparison of Figural Aftereffect Performance

\begin{tabular}{lrrrr} 
& $\begin{array}{c}\text { Male } \\
(\mathrm{N}=40)\end{array}$ & & $\begin{array}{c}\text { Female } \\
(\mathrm{N}=40)\end{array}$ \\
\cline { 1 - 2 } & + & & + & - \\
Field Independent & 15 & 5 & 13 & 7 \\
Field Dependent & 6 & 14 & 4 & 16 \\
& $\mathrm{x}^{2}=8.13$ & & $\mathrm{x}^{2}=8.28$ \\
& $\mathrm{p}<0.01$ & & $\mathrm{p}<0.01$ \\
\hline
\end{tabular}

The (+) column indicates the number of $S s$ showing figural aftereffects and the (-) column those who did not demonstrate the effect.

\section{REFERENCES}

DODWELL, P. C. Figural after-effects and field dependence: Another ground for skepticism. Psychonomic Science, 1969, 14, 84. 
IMMERGLUCK, L. Visual figural after-effects and field dependence. Psychonomic Science, 1966a, 4, 219-220.

IMMERGLUCK, L. Figural after-effects, rate of "figure-ground" reversal, and field dependence. Psychonomic Science, 1966b, 6, 45-46.

IMMERGLUCK, L. Further comments on "Is the figural aftereffect an aftereffect?" Psychological Bulletin, 1968, 70, 198-200.
PRESSEY, A. W., \& KOFFMAN, G. Figural aftereffects, illusions and the dimension of field dependence. Psychonomic Science, 1968, 10, 279-280.

\section{NOTE}

1. Supported by a U.S. Public Health Service research grant, $\mathrm{MH} \mathrm{14047-02.}$

\section{Negative incentive contrast effects with verbal reinforcement ${ }^{1}$}

\section{LAWRENCE WEINSTEIN ${ }^{2}$ and VINCENT MICHAEL COLUCCI, University of Maine, Portland, Maine 04103}

$A$ decrease in amount of reinforcement resulted in negative incentive contrast effects. This finding agrees with many studies involving animal Ss.

Negative incentive contrast effects are obtained when the performance of Ss exposed to a decrease in amount of reinforcement drops significantly below the performance of control Ss exposed to only the single lower reward magnitude. Investigations involving animal Ss have found that a decrease in incentive magnitude typically results in negative contrast effects. Crespi (1942) demonstrated that Ss exposed to a decrease in amount of reinforcement exhibited sudden decreases in performance that exceeded the levels of performance expected from the postshift magnitude of reinforcement. Negative incentive contrast effects have been observed in rats when using solid food (DiLollo \& Beez, 1966), and sucrose and saccharine (Weinstein, 1969). Little information is available concerning how human Ss respond to a decrease in amount of reinforcement. The present study attempted to determine how human Ss respond to a reduction in incentive magnitude.

\section{SUBJECTS}

The Ss were 15 male and 9 female undergraduate students enrolled in an introductory psychology course at the University of Maine, Portland. The Ss were assigned randomly to each of four equal groups.

\section{MATERIALS}

The materials consisted of a Kodak Carousel 750 slide projector, $5 \frac{1}{2} \mathrm{ft}$ from a $5 \%$-in. square piece of grey metal that served as a screen, $2 \times 1 \frac{1}{2}$ in. slides with digits typed on them (i.e., $776 \times 7$ ), and a stopwatch.

\section{PROCEDURE}

Each $S$ worked a sét of 15 mental multiplication problems. One answer or $30 \mathrm{sec}$ (whichever came first) was allowed for each problem, and there were $8 \mathrm{sec}$ between problems.

The problems were worked in four situations. Ss received no reinforcement after their answers $(\mathrm{N})$. Other Ss received a low (L) reward, one point, or a high $(\mathrm{H})$ reward, three points, after answering the 1st, 2nd, 4th, 6th, 9th, 10th, 11th, 12th, and 14th problems. And, finally, some individuals experienced a shift in reinforcement magnitude from high to low (S) after the 11 th problem.

The Ss who received $\mathrm{L}, \mathrm{H}$, or $\mathrm{S}$ were read the following instructions: "This is an experiment in abstract problem solving, the ability to rapidly work problems involving abstract reasoning. You will be given some problems to work. Each one consists of a three-digit number multiplied by a one-digit number. You are to mentally (without pencil and paper) multiply the numbers as quickly as you can and then tell me your answer. You will receive 0,1 , 2 , or 3 points after each answer. The closer

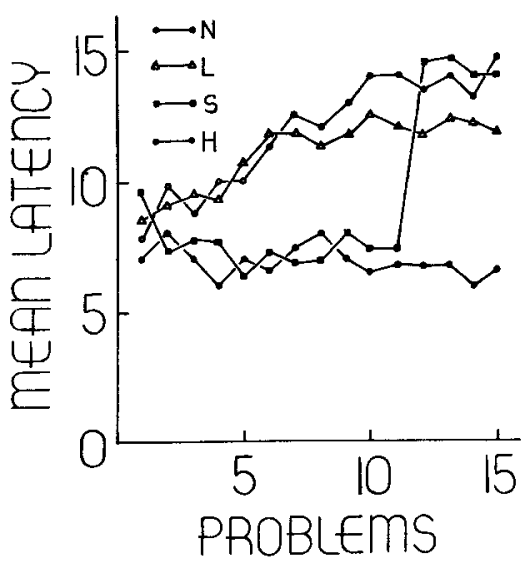

Fig. 1. Mean latency, in seconds, per problem. you are to being correct, the more points you will receive. You will be told perioddcally how you are doing."

In the instructions to the N Ss, reference to receiving points was omitted.

\section{RESULTS}

Latency means (the time between slide onset and the first response) were examined in the analysis of the results.

From Fig. 1, it appears that for Problems 1-11, the $S s$ in the $H$ condition took less time to answer than did the Ss in the $\mathrm{L}$ or $\mathrm{N}$ situations. It also seems that the Ss in the $\mathrm{N}$ condition took longer to answer than did the $\mathrm{Ss}$ in the $\mathrm{L}$ condition. The mean latency per problem from Problems 1-11 differed significantly among the four groups by analysis of variance $[F(3,20)=3.70, p<.05]$.

By Duncan's comparisons, the difference between $\mathrm{H}$ and $\mathrm{L}, \mathrm{H}$ and $\mathrm{N}, \mathrm{L}$ and $\mathrm{N}$ was each statistically significant $(p<.05)$, while the difference between $\mathrm{H}$ and $\mathrm{S}$ was not statistically reliable $(p>.05)$.

Figure 1 indicates that on Problem 12, S Ss abruptly increased their mean latency to a level below that of the $\mathrm{L}$ Ss (negative contrast effects). The mean latency per problem from Problems 12-15 differed significantly between the $S$ and $L$ Ss by an analysis of variance $[\mathrm{F}(1,10)=5.23$, $\mathrm{p}<.05]$.

\section{DISCUSSION}

The findings that for Problems 1-11 the $\mathrm{N}$ Ss took significantly more time to answer than any other Ss and that the H Ss took significantly less time to answer than the L Ss indicate that: (1) saying " 3 " or " 1 " after an answer served as a reinforcing event, and (2) two discriminably different levels of reinforcement were used.

The experiment demonstrated negative incentive contrast effects with a decrease in the amount of reinforcement.

This result agrees with many studies involving animal Ss (e.g., DiLollo \& Beez, 1966, Weinstein, 1969). It would appear that human Ss respond to a decrease in incentive magnitude as do many animal Ss.

\section{REFERENCES}

CRESPI, L. P. Quantitative variation in incentive and performance in the white rat. American Journal of Psychology, 1942, 55, 467-517.

DiLOLLO, V. D., \& BEEZ, V. Negative contrast effect as a function of magnitude of reward decrement. Psychonomic Science, 1966, 5, 99-100.

WEINSTEIN, L. Negative contrast effects with saccharine versus sucrose and continuous versus partial reinforcement. Paper presented at the meeting of the Eastern Psychological Association, Philadelphia, April 1969. NOTES

1. We thank Deborah Watkins for her help in planning the experiment.

2. Requests for reprints should be sent to Lawrence Weinstein, Department of Psychology, 96 Falmouth Street, University of Maine, Portland, Maine 04103. 